\section{Perencanaan Pembangunan Saluran Drainase Jalan Sulingan- Tanjung Selatan Ruas 122 Kecamatan Murung Pudak}

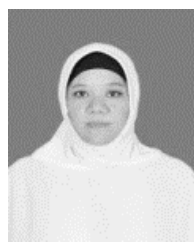

\section{Budiyarti}

Budiyarti lahir di Banjarbaru 7 Mei 1977. Lulus S1 Teknik Sipil Universitas Lambung Mangku-rat Banjarmasin tahun 2001. Bekerja di konsultan dari tahun 2002 sampai sekarang. Saat ini bekerja di perusahaan konsul-tan CV. ARUM CONSULINDO. Perusahaan tersebut berdomisi-li di Paringin Kabupaten Ba-langan, bergerak di bidang Jasa Konsultansi, Perencanaan dan Pengawasan.buletinppi@ulm.ac.id
Pembangunan, Pemeliharaan dan perbaikan drainase secara rutin maupun berkala dapat mengurangi kerusakan pada jalan dan mengurangi genangan air di permukiman. Perencanaan pembangunan saluran drainase ini berada di wilayah Kecamatan Murung Pudak, saluran yang direncanakan merupakan pembangunan baru, sebelumnya di lokasi tersebut hanya ada saluran alam yang terbentuk dari aliran air hujan. Kontrak kerja perencanaan ini selama satu bulan dengan panjang yang direncanakan 2.733 meter di dua sisi jalan. Selain saluran drainase juga dibangun bangunan pelengkap seperti gorong-gorong. Lingkup pekerjaan perencanaan pada proyek ini meliputi pengumpulan data pendukung, survey lokasi rencana pekerjaan dan pengukuran lapangan untuk mendapatkan data yang akurat, dokumentasi Infrastruktur kondisi awal (0\%), penyusunan pra rencana yaitu pembuatan gambar sket dan rab rencana penanganan, pembuatan gambar kerja, penyusunan bill of quantity (BQ) dan spesifikasi teknis, serta pembuatan Laporan akhir

www.buletinppi.ulm.ac.id

\section{Pendahuluan}

Jalan dan drainase memiliki fungsi yang saling berhubungan. Drainase merupakan salah satu prasarana pendukung jalan. Dengan drainase yang baik, maka jalan pun akan berfungsi dengan baik.

Kebutuhan akan prasarana drainase yang baik merupakan hal yang sangat diharapkan oleh masyarakat sekitar dan pengguna jalan. Kondis drainase yang ada saat ini di wilayah perencanaan yaitu di Jalan Sulingan-Tanjung Selatan Ruas 122 Kecamatan Murung Pudak masih sangat kurang (Gambar 1). Saluran yang ada hanya saluran alam yang terbentuk oleh aliran air hujan. Dengan tidak adanya saluran maka akan berdampak pada genangan air di badan jalan, genangan di areal perkebunan serta permukiman yang berada dekat dengan jalan.

Salah satu penyebab konstruksi jalan yang rusak yaitu tidak adanya saluran drainase yang baik sehingga apabila terjadi hujan akan mengakibatkan genangan pada badan jalan yang dampaknya lama kelamaan akan merusak struktur lapisan jalan.

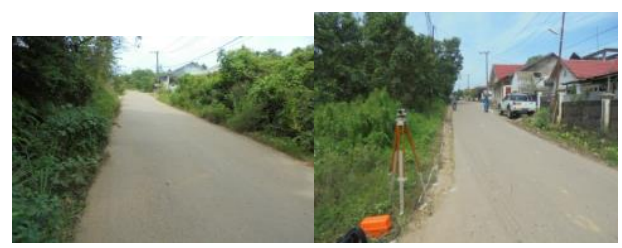

Gambar 1. Kondisi eksisting drainase Jalan Sulingan - Tanjung Selatan (sumber dok .proyek)
Paper ini membahas perencanaan pembangunan saluran drainase jalan Sulingan - Tanjung Selatan Ruas 122 Kecamatan Murung Pudak. Letak drainase tersebut menghubungkan dua jalan kabupaten. Nama kegiatan perencanaan ini adalah Perencanaan Teknis Pembangunan Saluran Drainase/Gorong-gorong di Wilayah Tengah dengan menggunakan dana APBD Kabupaten Tabalong Tahun Anggaran 2017. Rencana penanganan yang akan dilakukan antara lain pembangunan saluran drainase terbuka menggunakan pasangan batu gunung, dan bangunan pendukung yaitu gorong-gorong pipa beton dan jembatan plat.

Beberapa langkah yang diambil dalam kegiatan perencanaan drainase ini antara lain melakukan koordinasi ke Dinas Pekerjaan Umum dan Penataan Ruang bidang Bina Marga untuk mendapatkan datadata pendahuluan, koordinasi daerah/lokasi pekerjaan (terutama kepala desa/ketua RT) untuk mendapatkan data lokasi pekerjaan yang diusulkan. Langkah selanjutnya melakukan pengumpulan data lapangan apa-apa saja rencana penanganan yang akan dilakukan, membuat sketsa gambar dan Rab rencana yang kemudian dikonsultasikan ke instansi terkait, mengakomodir masukan-masukan yang diberikan pengelola kegiatan dan kemudian membuat gambar detail serta RAB keseluruhan. Kegiatan selanjutnya adalah membantu Pengelola kegiatan mempersiapkan dokumen pelelangan. 


\section{Hasil Kerja}

Uraian singkat tentang lokasi yang menjadi objek pengamatan yaitu saluran yang direncanakan berada di ruas jalan Kabupaten ke Jalan kabupaten, di sekitar jalan terdapat permukiman masyarakat, dan lokasi perencanaan berada di pinggiran kota. Karena lokasi perencanaan berada di wilayah pinggiran kota maka saluran direncanakan menggunakan saluran terbuka.

Panjang saluran yang direncanakan $2.733 \mathrm{~m} \times 2$ sisi dengan dimensi lebar atas $70 \mathrm{~cm}$, lebar bawah $50 \mathrm{~cm}$, tinggi $80 \mathrm{~cm}$ (dimensi penampang basah) pada kiri dan kanan jalan. Pada persimpangan jalan dibuat goronggorong pipa beton dan jembatan plat beton untuk akses masuk ke komplek maupun halaman rumah masyarakat. Site plan dan denah lokasi pekerjaan terlihat pada Gambar 2.

Sebelum dilakukan pemasangan batu gunung terlebih dahulu dilakukan galian tanah menggunakan alat berat, kemudian dilakukan pemasangan batu gunung sebagai konstruksi saluran drainase. Pada bagian atas dan dinding saluran bagian dalam dilakukan plesteran agar saluran terlihat rapi dan dibagian lantai dilakukan pengecoran dengan ketebalan $10 \mathrm{~cm}$ dengan menggunakan beton mutu rendah $\mathrm{fc}^{\prime} 10 \mathrm{MPa}$. Di persimpangan maupun jalan masuk komplek perumahan dibangun gorong-gorong pipa beton bertulang dan dibuat jembatan plat di setiap rumah untuk akses masuk halaman. Jenis pekerjaan dan volume yang direncanakan dirangkum pada Tabel 1.

Gambar 3 memperlihatkan potongan melintang drainase yang direncanakan. Dimensi galian tanah saluran adalah lebar atas $120 \mathrm{~cm}$, lebar bawah $100 \mathrm{~cm}$ dan kedalaman galian $90 \mathrm{~cm}$. Sedangkan dimensi penampang basah saluran adalah lebar permukaan atas $70 \mathrm{~cm}$, tinggi $80 \mathrm{~cm}$ dan lebar lantai $50 \mathrm{~cm}$. Konstruksi yang digunakan adalah pasangan batu gunung dengan ketebalan dinding saluran $25 \mathrm{~cm}$. Pada bagian lantai saluran dilakukan pengecoran dengan ketebalan $10 \mathrm{~cm}$ dengan beton mutu rendah $\mathrm{fc}^{\prime} 10 \mathrm{MPa}$.

Dari perhitungan RAB, total dana yang dibutuhkan untuk pekerjaan seperti terlihat pada Tabel 1 adalah sebesar Rp. 4.306.848.000,- (empat milyar tiga ratus enam juta delapan ratus empat puluh delapan ribu rupiah).

\section{Kesimpulan}

Pada pekerjaan Perencanaan Pembangunan Saluran Drainase Jalan Sulingan - Tanjung Selatan dapat ditarik kesimpulan bahwa pekerjaan yang akan dilaksanakan yaitu Mobilisasi, manajemen keselamatan lalu lintas, galian tanah, pasangan batu dengan mortar, goronggorong pipa beton bertulang, plesteran, beton mutu sedang fc'20 MPa, beton mutu rendah $\mathrm{fc}^{\prime} 10 \mathrm{MPa}$, baja tulangan serta pondasi cerucuk. Dengan Pagu dana sebesar Rp. 4.306.848.000,- (empat milyar tiga ratus enam juta delapan ratus empat puluh delapan ribu rupiah).

Tabel 1. Jenis dan volume pekerjaan yang direncanakan (CV. Arum Consulindo, 2017)

\begin{tabular}{|c|c|c|}
\hline UraianKerja & Volume & Satuan \\
\hline Mobilisasi & 1,00 & Ls \\
\hline $\begin{array}{l}\text { Manajemen dan keselamatan } \\
\text { lalu lintas }\end{array}$ & 1,00 & Ls \\
\hline Galian Biasa & $4.945,22$ & $\mathrm{~m}^{3}$ \\
\hline Pasangan batu dengan mortar & $2.466,90$ & $m^{3}$ \\
\hline $\begin{array}{l}\text { Gorong-gorong pipa beton } \\
\text { bertulang }\end{array}$ & 84,00 & $\mathrm{~m}^{\prime}$ \\
\hline Plesteran & $11.482,20$ & $m^{2}$ \\
\hline Beton mutu sedang fc' $20 \mathrm{MPa}$ & 148,96 & $m^{3}$ \\
\hline Beton mutu rendah fc'10 MPa & 273,72 & $\mathrm{~m}^{3}$ \\
\hline Baja tulangan U24 polos & $5.185,76$ & $\mathrm{~kg}$ \\
\hline Pondasi cerucuk & 507,00 & $\mathrm{~m}^{\prime}$ \\
\hline
\end{tabular}

\section{Referensi}

1 CV. Arum Consulindo, DED/ Laporan Akhir Perencanaan Pembangunan Saluran Drainase Jalan Sulingan - Tanjung Selatan Ruas 122 Kecamatan Murung Pudak, Dinas PU dan Penataan Ruang Kab.Tabalong Bidang Bina Marga, 2017

2 Spesifikasi Umum Bina Marga Revisi 2, Kementerian PU RI, 2010

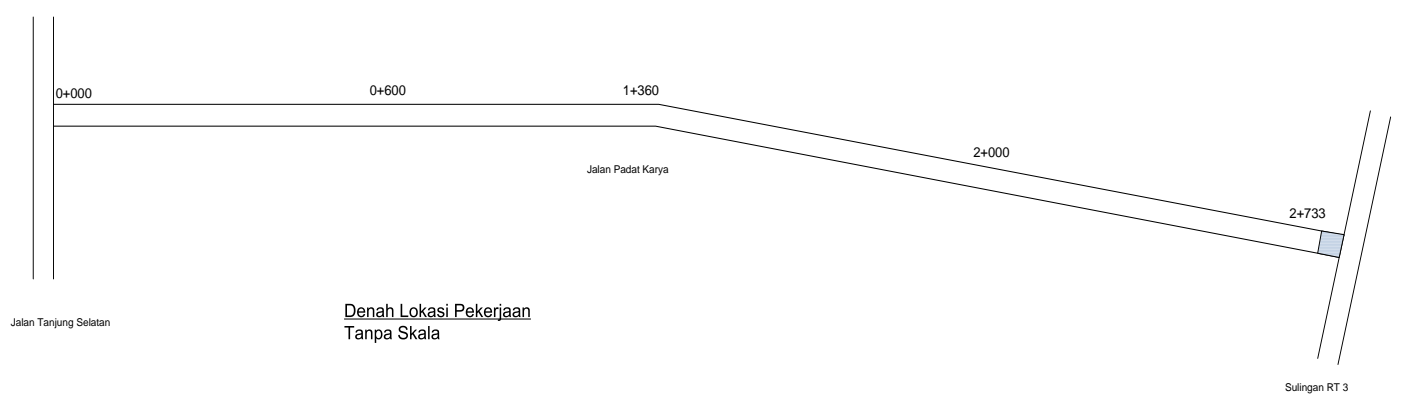

Gambar 2. Denah lokasi pekerjaan (CV. Arum Consulindo, 2017) 


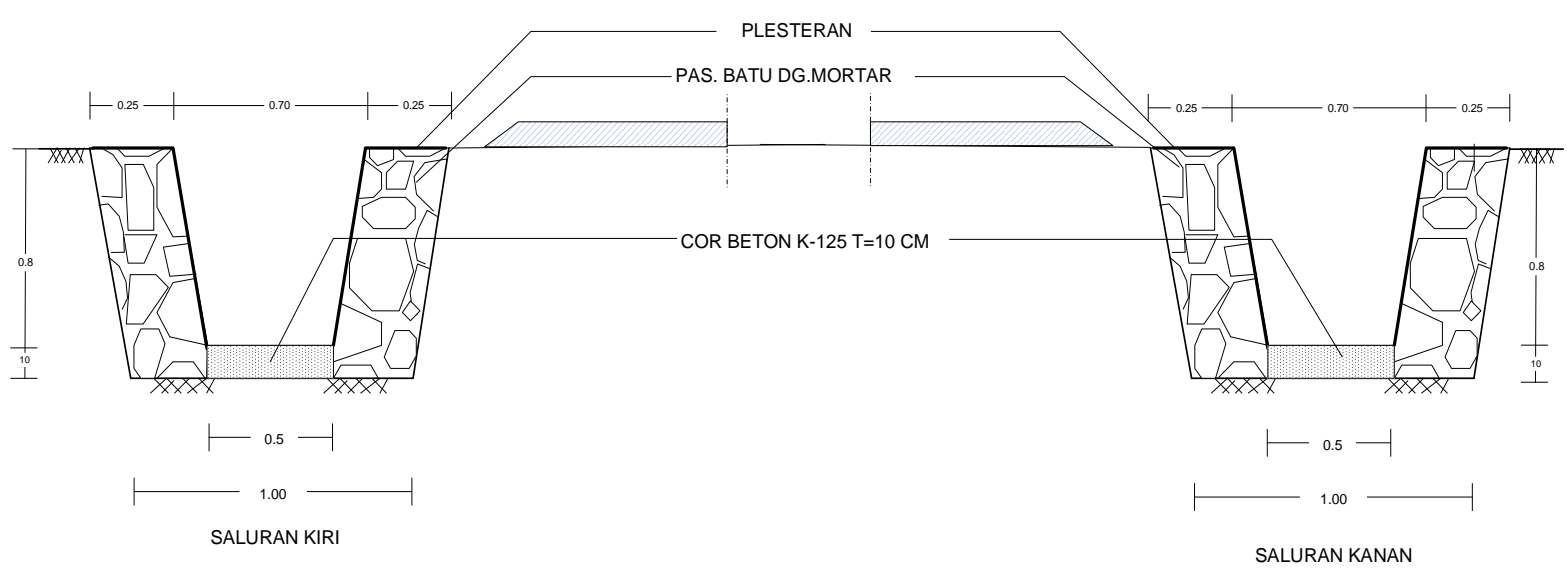

Gambar 3. Potongan perencanaan pembangunan saluran drainase Jalan Sulingan - Tanjung Selatan (CV. Arum Consulindo, 2017) 